http://jmscr.igmpublication.org/home/

ISSN (e)-2347-176x ISSN (p) 2455-0450

crossref DOI: https://dx.doi.org/10.18535/jmscr/v7i7.163

Journal Of Medical Science And Clinical Research

\title{
Hansen Disease Mimicking Acute Urticaria
}

\author{
Authors \\ Kuldeep Verma ${ }^{1}$, Saru Thakur ${ }^{2 *}$, G.R. Tegta ${ }^{3}$, Ghanshyam Verma ${ }^{4}$, Mudita Gupta ${ }^{5}$, \\ Ajeet Negi ${ }^{6}$, Reena Kumari Sharma ${ }^{7}$ \\ ${ }^{1,2}$ Post graduate student, ${ }^{3}$ Professor and Head, ${ }^{4}$ Associate Professor, ${ }^{5}$ Assistant Professor, ${ }^{6,7}$ Senior Resident, \\ Deptt. of Dermatology, Leprosy and Venereology, Indira Gandhi Medical College, Shimla, \\ Himachal Pradesh \\ *Corresponding Author \\ Saru Thakur \\ Deptt. of Dermatology, Leprosy and Venereology, Indira Gandhi Medical College, Shimla, \\ Himachal Pradesh
}

\begin{abstract}
Leprosy is a slowly progressive disease with a low infectivity caused by mycobacterium leprae which primarily targets the skin and peripheral nerves. The cutaneous manifestations are numerous in leprosy and it can mimic many dermatoses. In non endemic areas and especially after elimination, a practitioner confronted with an acute or chronic atypical rash that is non responsive to treatment, usually do not have leprosy as a differential diagnosis. We present a case of Hansens disease in type 1 reaction that was wrongly diagnosed and managed as a case of urticaria before coming to our centre. Thus any atypical cutaneous presentation which is not responding to conventional treatment should include Hansen disease as differential diagnosis.
\end{abstract}

Keywords: hansen, urticaria, type 1 reaction.

\section{Introduction}

Leprosy is a chronic disease caused by Mycobacterium leprae which has predilection for skin and peripheral nerves ${ }^{[1]}$. The characteristic lesions vary widely depending on the spectrum of disease and range from a well-defined large plaque of Tuberculoid leprosy with a definite anaesthesia to ill defined hypopigmented macules with intact sensations of Lepromatous Leprosy ${ }^{[1]}$. However, lesions of Hansen disease are not always characteristic of the disease and may mimic variety of different dermatoses like psoriasis and urticaria ${ }^{[2,3]}$.

\section{Case Report}

A 28 years old married female presented with chief complaints of red, raised swelling over the face, trunk and extremities from last 3 days along with mild fever. The swelling was mildly itchy, painless and non-oozy. She was managed as a case of Urticaria at peripheral health facilities but was not relieved with anti-histaminics. She was referred for further management to department of dermatology in the teriary care centre. The detailed history was extracted and it was found that patient had history of tingling and numbness for which she was consulting in neurology from last 5 years. There was also history of spontaneous 
blistering over hands and feet. From last 2 years, there was history of slipping of slippers and dropping of utensils. The patient had delivered a full term infant by normal vaginal delivery about 6 weeks back.

On Examination, general physical examination was within normal limits. Muco-cutaneous examination revealed involvement of sites such as face, neck, upper and lower limbs (Extensor> Flexor) and trunk (Back> Front).Over the above sites, there were 12 well defined erythematous, edematous, annular to polycyclic plaques of size $2 \times 2 \mathrm{~cm}$ to $40 \times 30 \mathrm{~cm}$ approximately, with pseudopodia, satellite lesions and peripheral scaling at places (figure $a, b)$. Sensory examination revealed loss of temperature in the right upper limb and loss of touch in lower $1 / 3^{\text {rd }}$ and $50 \%$ loss of pain below elbow and $100 \%$ loss of pain below wrist. In the left upper limb, there was loss of temperature and touch below wrist and 50\% loss of pain below elbow and $100 \%$ loss of pain below wrist. In bilateral lower limbs, there was loss of temperature and $100 \%$ loss of touch in lower $1 / 3^{\text {rd }}$ of lower limb while there was $90 \%$ loss of pain in lower $1 / 3^{\text {rd }}$ bilaterally. There was loss of temperature, touch $(100 \%)$ and pain $(90 \%)$ over the lesions. Test for Ulnar nerve (Egawa, Book and Card test) were weak while Opposition and Pen test were weak in median nerve function assessment bilaterally. There was thenar and hypothenar atrophy with guttering in left hand.Nerve Examination revealed involvement ofUlnar nerve $(2+, \mathrm{B} / \mathrm{L})$ Radial cutaneous nerve $(2+$, Right), Lateral popliteal nerve $(1+$ Left and $2+$ Right) and posterior tibial nerve (2+ Right with Grade I Neuritis and 1+ Left).

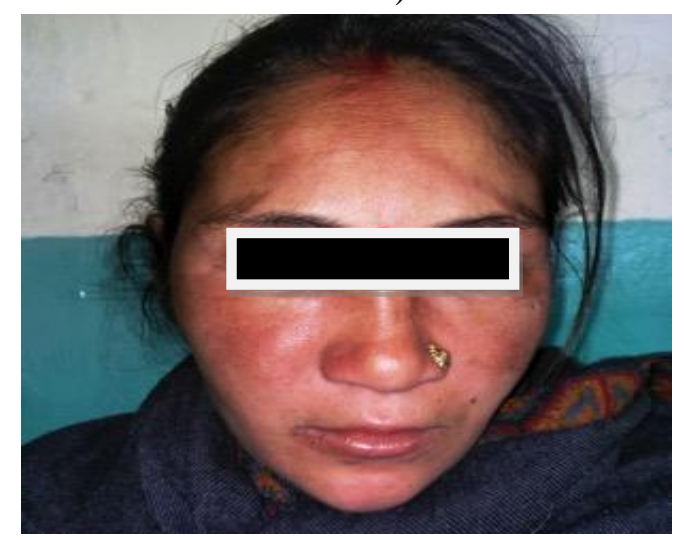

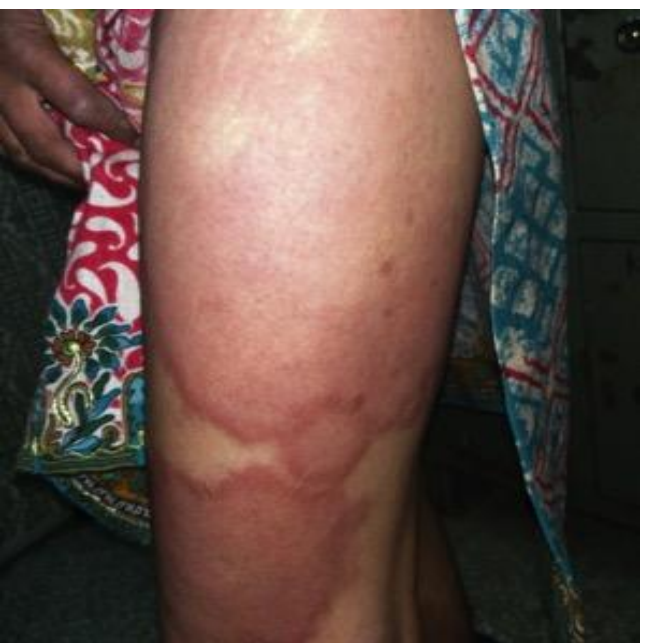

Figure: Edematous, erythematous plaques over (a) face and (b) thigh mimicking Acute Urticaria.

Routine blood and urine investigations were normal except liver functions (AST $=106 \mathrm{U} / \mathrm{L}$, ALT $=128 \mathrm{U} / \mathrm{L}$, Bilirubin $2.0 \mathrm{mg} \%$ ).Immune status was non-reactive.Slit skin smears were negative both lesionally and from bilateral ears. Ocular examination revealed no abnormalities. The patient was finally diagnosed as a case of Borderline Tuberculoid downgrading to midBorderline Hansen disease with Grade II deformity hands, Grade I deformity feet and Grade 0 deformity eyes, in severe Type 1 reaction.

\section{Discussion}

Leprosy has a wide range of presentations which can mimic various other dermatoses like psoriasis, dermatitis, granulomatous disorders like sarcoid, leishmaniasis etc. The differential diagnosis is so wide that one has to exclude wide variety of dermatological diseases before stamping it to be leprosy as stigma is still associated to it ${ }^{[4]}$. The chronic smooth progressive course of leprosy is interrupted by episodes of acute inflammation called as reactions.

Leprosy reactions are immunologicallymediated phenomena that occur before, during or after the completion of multi-drug therapy. There are two types of reactions in leprosy i.e. type 1 reaction (T1R) and erythema nodosumleprosum (ENL) ${ }^{[5]}$. These distinct conditions occur separately but rarely may arise at different times in the same patient. It is important to recognize that both these 
conditions can result in permanent loss of nerve function and hence be a cause of great morbidity.

A T1R is characterized by the development of acute inflammation in skin lesions or nerves or both. Borderline spectrum of leprosy is a strong risk factor for the occurrence of T1Rs but rarely, individuals with polar forms of leprosy may also experience T1Rs. The onset of a T1R may be very rapid and are frequently recurrent and this can lead to further nerve damage. In this type of reaction, skin lesions become acutely inflamed, oedematous and rarely may ulcerate. When oedematous, these lesions can resemble acute urticarial rash and may be misdiagnosed as simple urticaria as seen in our case. The urticarias are characterized by short-lived swellings of the skin and mucosa due to plasma leakage and it is commonly used to describe an eruption of weals and or angioedema which are generally itchy and edematous. However, on keen observation and examination, one can discover other signs pertaining to leprosy.

Oedema of the hands, feet and face can also be a feature of a reaction but systemic symptoms are unusual. Later on, skin lesions develop scaling in the chronic phase of T1R and may then resemble psoriasis, dermatophytic infections and cutaneous T-cell lymphoma.

The triggers for T1R include spectrum of disease (borderline forms), female gender, multiple or disseminated patches, previous history of reaction, large facial patches, Multidrug therapy initiation itself, hepatitis B or C and immunotherapy. Improvement in cell mediated immunity seems to be the cause of reaction. In our patient, improvement in immunity after delivery may be considered as the trigger of T1R.

Reactions contribute significantly to the burden of leprosy and must be diagnosed and treated early to prevent nerve function impairment and hence, permanent disability. Our patient was a case of Hansen disease in Type I reaction which was initially misdiagnosed and treated as a case of urticaria. Lactation was the most probable trigger for precipitating Type I reaction in our patient.

\section{Conclusion}

Although diagnosis of urticaria is straight foreword in most patients, on occasion, it may require additional consideration, as many cutaneous and systemic diseases may manifest with urticaria-like lesions. Hence necessary vigilance should be kept in leprosy presenting with atypical presentions like urticarial eruptions as in this case.

\section{Conflict of Interest: Nil. \\ Declaration of Patient Consent}

The authors certify that they have obtained all appropriate patient consent forms, in which, the patient has given her consent for her images and other clinical information to be reported in the journal. The patient understands that name and initials will not be published and due efforts will be made to conceal identity, but anonymity cannot be guaranteed.

\section{Financial Support and Sponsorship: Nil. Sources of support: nil}

\section{References}

1. Ridling DS, Jopling WH. Classification of leprosy according to immunity. A five group system. Int J Lepr Other Mycobact Dis. 1966;34(3):255-273.

2. Vora RV, Pilani AP, Jivani N, Kota RK. Leprosy Mimicking Psoriasis. J Clin and Diagn Res. 2015;9(9):WJ01-WJ02.

3. Song $\mathrm{Z}$ et al. A case of borderline leprosy presenting with urticaria-like eruptions: are there lessons to be learned for allergists? Allergy. 2011;66(12):1622-4.

4. Raval RC. Various faces of Hansen's disease. Indian J Lepr.2012;84:155-600.

5. Kahawita IP, Walker SL, Lockwood DNJ. Leprosy type 1 reactions and erythema nodosumleprosum. An Bras Dermatol. 2008;83(1):75-82. 